\title{
LA TITULARIDAD COMPARTIDA DE LAS EXPLOTACIONES AGRARIAS COMO MEDIDA «BIDIRECCIONAL»*
}

\author{
The shared ownership of agricultural exploitations \\ as a "bidirectional" measure
}

\author{
María Dolores Cabello Fernández \\ Profesora Contratada Doctora de Derecho Constitucional \\ Universidad de Málaga \\ cabello@uma.es \\ doi: http://dx.doi.org/10.18543/ed-66(1)-2018pp253-279
}

Recibido: 12.04 .2018

Aceptado: 25.06.2018

\section{Resumen}

En este trabajo, se trata de analizar el marco constitucional sobre la igualdad de género, la titularidad compartida de las explotaciones agrarias y la no discriminación por razón de género en función del ordenamiento jurídico constitucional español que regula con carácter general la igualdad entre mujeres y hombres (artículo $14 \mathrm{CE}$ ) y la obligación de los poderes públicos de remover los obstáculos para que la igualdad sea real y efectiva (artículo 9.2 CE).

\section{Palabras clave}

Exploraciones agrarias; titularidad compartida; igualdad real y efectiva; género.

* Cómo citar / Citation 'Chicago-Deusto' (Autor-fecha / Author-date / Lista de referencias / Reference list entries): Cabello Fernández, María Dolores. 2018. «La titularidad compartida de las explotaciones agrarias como medida "bidireccional"». Estudios de Deusto 66, n. ${ }^{\circ}$ 1: 253-279. doi: http://dx.doi.org/10.18543/ed-66(1)-2018pp253-279. 


\section{Abstract}

In this paper, it is about analyzing the constitutional framework on gender equality, shared ownership of agricultural holding and non-discrimination on the grounds of gender according to the Spanish constitutional legal system that regulates equality between women and men (article 14 of the Spanish Constitution) and the obligation of public authorities to remove obstacles to make equality real and effective (article 9.2 of the Spanish Constitution).

\section{Keywords}

Agricultural holding; shared ownership; real and effective equality; gender. 


\begin{abstract}
Sumario: I. Introducción. II. El Derecho Europeo sobre El PAPEL DE las mujeres en las explotaciones agrarias. III. Marco LEGISLATIVO DE REFERENCIA SOBRE LA TITULARIDAD COMPARTIDA DE LAS EXPLOTACIONES AGRARIAS: LA LEY ORGÁNICA 3/2007, DE 22 DE MARZO, PARA LA IGUALDAD EFECTIVA DE MUJERES Y HOMBRES. IV. ESTUdio Comparativo DEl Desarrollo en la Normativa DE las CoMUNIDADES AUTÓNOMAS SOBRE TITULARIDAD COMPARTIDA DE LAS EXPLOTACIONES AgRARIAS. V. ANÁlisis DE LA LEY 35/2011, DE 4 DE octubre, SOBRE TITULARIDAD COMPARTIDA DE LAS EXPLOTACIONES AgraRias. VI. ANÁlisis DE DERECHO COMPARADO SOBRE IGUALDAD Y Explotaciones Agrarias: Francia e ItAlia. VII. La Titularidad COMPARTIDA COMO MEDIDA «BIDIRECCIONAL». VIII. CONCLUSIONES. BIBLIOGRAFÍA.
\end{abstract}

\title{
I. INTRODUCCIÓN
}

La no discriminación por razón de género se consagra en el artículo 14 de la Constitución Española (CE) de 1978 cuando establece que «Los españoles son iguales ante la ley, sin que pueda prevalecer discriminación alguna por razón de nacimiento, raza, sexo, religión, opinión, o por cualquier otra condición o circunstancia personal o social». Este reconocimiento del derecho a la igualdad conecta con la forma de Estado, ya que el Estado de Derecho se caracteriza por el reconocimiento de un conjunto de derechos a la ciudadanía. Y España, como Estado social y democrático de Derecho, reconoce la igualdad como derecho fundamental en el artículo 14 de la Constitución de 1978. La naturaleza jurídica de la igualdad como derecho fundamental es la de un derecho público subjetivo, es decir, la facultad de la ciudadanía de exigir a los poderes públicos el respeto a un ámbito de libertad. Además, la ciudadanía titular de ese derecho a la igualdad puede protegerlo ante la jurisdicción ordinaria $\mathrm{y}$, en su caso, ante el Tribunal Constitucional mediante el recurso de amparo. A esto hay que añadir que la configuración como norma suprema de la Constitución hace que todo el ordenamiento jurídico deba respetarla, de tal modo que el legislador ordinario, el Parlamento estatal, o las Asambleas legislativas de las Comunidades Autónomas, no pueden elaborar una ley contraria a esa igualdad reconocida en la Constitución y, si lo hicieran, esa ley podría ser expulsada del ordenamiento a través de su declaración de inconstitucionalidad por el Tribunal Constitucional. El artículo 9.2 de la Constitución consagra la que se denomina igualdad material. El 9.2 CE contiene un mandato a los poderes públicos para que remuevan los obstáculos para que la igualdad sea real y efectiva $\mathrm{y}$, este mandato, es el fundamento de las acciones positivas, entendidas 
como medidas de discriminación positiva justificadas en una situación de desigualdad previa que hay que corregir ${ }^{1}$.

Se han definido las acciones positivas como «medidas específicas de intervención que actúan sobre las barreras sociales que dificultan la igualdad de oportunidades entre mujeres y hombres $»^{2}$. Y que, según la jurisprudencia del TJUE, suponen una excepción al principio de igualdad que no tiene, por tanto, carácter absoluto, excepción que permitirá un trato distinto cuando se justifique por motivos de objetividad y proporcionalidad, y que por ser una excepción deben interpretarse con carácter restrictivo ${ }^{3}$.

La igualdad como derecho fundamental goza de un sistema de garantías, como la vinculación de los poderes públicos a los derechos fundamentales, vinculación que se extiende a la ciudadanía, en lo que se denomina la eficacia de los derechos fundamentales entre particulares (art. 9.1 CE). Otra garantía es la reserva de ley orgánica para su desarrollo legislativo, ley que deberá respetar el contenido esencial del derecho fundamental. Y como garantías jurisdiccionales se establece un procedimiento preferente y sumario ante la jurisdicción ordinaria (amparo ordinario) y el recurso de amparo ante el Tribunal Constitucional (amparo constitucional) (art. $53 \mathrm{CE}$ ). Así como, la necesidad de seguir el procedimiento agravado para la reforma de la Constitución que afecte a derechos fundamentales (art. $168 \mathrm{CE})^{4}$.

Este marco constitucional conecta con la titularidad compartida de las explotaciones agrarias en la medida en que configurar un derecho de acceso a la titularidad de las explotaciones agrarias supone una concreción del derecho a la igualdad, por lo que conecta con el artículo $14 \mathrm{CE}$ y, por lo tanto, con todo el sistema de garantías propio de un derecho fundamental. Y, también conecta con el artículo 9.2 CE porque la situación fáctica de invisibilidad del trabajo de las mujeres en las explotaciones agrarias es precisamente una desigualdad que compete a los poderes públicos corregir.

${ }^{1}$ La desigualdad entre sexos dentro de la forma de Estado se aborda desde la teoría feminista por Mackinnon 1995.

2 Sevilla Merino, Ventura Franch y García Campá 2005: 69-71.

${ }^{3}$ Cfr. Freixes Sanjuán 2000: 51.

4 Sobre el derecho fundamental a la igualdad cfr. Balaguer Callejón 2010. Sobre la desigualdad y el género en el discurso, cfr. Tannen 1966. Un estudio de la igualdad como cuestión de justicia en Monereo Atienza 2010. La igualdad desde el punto de vista de la sociología ha sido tratada por Saltzman 1992 que analiza las bases de la desigualdad entre sexos y formula una teoría integrada dirigida a la igualdad entre los sexos. Ana De Miguel en su obra Neoliberalismo sexual estudia la ideología neoliberal que convierte a las personas en mercancía, e incluso a la mujer, al cuerpo de la mujer, a través de la industria del sexo patriarcal, pero bajo la falacia de la libertad para elegir de las mujeres, y por ello habla del «mito de la libre elección». Cfr. De Miguel 2015. 


\section{EL DERECHO EUROPEO SOBRE EL PAPEL DE LAS MUJERES EN LAS EXPLOTACIONES AGRARIAS}

En 1950 se firmó el Convenio número 177, del Consejo de Europa, el Convenio Europeo para la Protección de los Derechos Humanos y Libertades Fundamentales, que fue ratificado por España el 26 de septiembre de 1979 y publicado en el Boletín Oficial del Estado de 10 de octubre de 1979. El artículo 14 de este Convenio ya consagró la prohibición de discriminación, estableciendo que: «El goce de los derechos y libertades reconocidos en el presente Convenio ha de ser asegurado sin distinción alguna, especialmente por razones de sexo, raza, color, lengua, religión, opiniones políticas u otras, originen nacional o social, pertenencia a una minoría nacional, fortuna, nacimiento o cualquier otra situación $»^{5}$.

La Unión Europea es la fórmula jurídica-política que vertebra Europa, y donde España está integrada. La Unión formula su propio Derecho que vincula a los Estados miembros, partiendo de los Tratados constitutivos. Actualmente, rige el Tratado de la Unión Europea, que es la norma básica de funcionamiento de la Unión, donde se establecen los principios y directrices que van a gobernar su acción.

El principio de igualdad se formula en el propio Tratado de la Unión Europea $^{6}$. Primero como valor esencial de la Unión. Así, en su artículo 2 se establece que: «La Unión se fundamenta en los valores de respeto de la dignidad humana, libertad, democracia, igualdad, Estado de Derecho y respeto de los derechos humanos, incluidos los derechos de las personas pertenecientes a minorías. Estos valores son comunes a los Estados miembros en una sociedad caracterizada por el pluralismo, la no discriminación, la tolerancia, la justicia, la solidaridad y la igualdad entre mujeres y hombres».

En el artículo 3.3 es finalidad de la Unión fomentar la igualdad entre mujeres y hombres. Concretamente, «La Unión combatirá la exclusión social y la discriminación y fomentará la justicia y la protección sociales, la igualdad entre mujeres y hombres, la solidaridad entre las generaciones y la protección de los derechos del niño».

Y; específicamente, se consagra la igualdad por razón de sexo, en el artículo 8 del Tratado de funcionamiento de la Unión Europea (antiguo artículo 3, apartado 2, TCE): «En todas sus acciones, la Unión se fijará el objetivo de eliminar las desigualdades entre el hombre y la mujer y promover su igualdad».

${ }^{5}$ Un estudio sobre la igualdad en el Convenio Europeo de Derechos Humanos y en la jurisprudencia del Tribunal de Estrasburgo en Freixes Sanjuán 2000: 59-64.

${ }^{6}$ Una evolución de la igualdad entre las mujeres y los hombres en el derecho comunitario desde su reconocimiento originariamente en el art. 119 del Tratado CEE se puede consultar en Freixes Sanjuán 2000: 45-47. Sobre la igualdad en el Tratado de Amsterdam, cfr. Ibídem: 51-53. 
También, el Tratado de funcionamiento de la Unión Europea, dedica el Título X a la política social, estableciendo el artículo 151 (antiguo artículo 136 TCE): «La Unión y los Estados miembros, teniendo presentes derechos sociales fundamentales como los que se indican en la Carta Social Europea, firmada en Turín el 18 de octubre de 1961, y en la Carta comunitaria de los derechos sociales fundamentales de los trabajadores, de 1989, tendrán como objetivo el fomento del empleo, la mejora de las condiciones de vida y de trabajo, a fin de conseguir su equiparación por la vía del progreso, una protección social adecuada, el diálogo social, el desarrollo de los recursos humanos para conseguir un nivel de empleo elevado y duradero y la lucha contra las exclusiones». Y, para conseguir estos objetivos, el artículo 153 establece que la Unión «apoyará y completará la acción de los Estados miembros en los siguientes ámbitos: i) la igualdad entre hombres y mujeres por lo que respecta a las oportunidades en el mercado laboral y al trato en el trabajo.

Hay un documento básico, que analizamos, que es el Dictamen del Comité Económico y Social sobre «El papel de la mujer rural en el desarrollo sostenible de la agricultura de la Unión Europea», (2000/C 204/07), publicado en el Diario Oficial de la Unión Europea de 18 de julio del 2000. Este Dictamen parte de la consideración de que «La Unión Europea cuenta con una política en materia de mujer rural que, hasta después de la aprobación de la Agenda 2000, no se aplicaba de forma práctica en su totalidad. Se considera a la mujer como pieza clave del desarrollo rural y, en este sentido, el interés de este Dictamen es abordar cuestiones que se refieren al desarrollo y la diversificación integrales de las zonas rurales.

Según el punto 3.1.2 de este Dictamen «La noción de «agricultura» abarca la de la mujer que trabaja en la agricultura, ya sea titular de la explotación, cotitular o cónyuge de un agricultor que trabaja a tiempo completo o a tiempo parcial en la explotación». Las estadísticas, en el año 2000, reflejaban que las mujeres representaban una tercera parte de la población activa agrícola, ya que del $34 \%$ del total, sólo un $10 \%$ eran titulares de explotaciones.

Considera a las mujeres y a los jóvenes factores decisivos de cambio, y constata la cada vez mayor implicación de las mujeres en el sector agrícola. Pero su situación es diversa según los distintos países. Aunque existen dificultades comunes como falta de formación, el desarrollo de trabajos no remunerados, acceso restringido a la propiedad, ausencia de participación en la toma de decisiones, dificultades de acceso al crédito. Y para conjurar esta situación considera que los Gobiernos del Mediterráneo deben imponerse como prioritaria la tarea de alcanzar la igualdad de oportunidades entre hombres y mujeres en la agricultura y el medio rural.

La más reciente Directiva 2010/41/UE del Parlamento Europeo y del Consejo, de 7 de julio de 2010, sobre la aplicación del principio de igualdad 
de trato entre hombres y mujeres que ejercen una actividad autónoma, y por la que se deroga la directiva 86/613/CEE del Consejo, debe aplicarse a los trabajadores autónomos y a sus cónyuges o, cuando y en la medida en que estén reconocidas en el Derecho nacional, a sus parejas de hecho, siempre que participen habitualmente en las actividades de la empresa en las condiciones establecidas por el Derecho nacional. A fin de mejorar la situación de dichos cónyuges y, cuando y en la medida en que estén reconocidas en el Derecho nacional, de las parejas de hecho de los trabajadores autónomos, su trabajo debe reconocerse.

En el ámbito del trabajo autónomo, la aplicación del principio de igualdad de trato significa que no debe haber ningún tipo de discriminación por razón de sexo, por ejemplo, en relación con la creación, el equipamiento o la ampliación de una empresa o con el inicio o la ampliación de cualquier otra forma de actividad autónoma.

Partiendo del artículo 157, apartado 4, del Tratado de Funcionamiento de la Unión Europea, los Estados miembros pueden mantener o adoptar medidas que ofrezcan ventajas concretas destinadas a facilitar al sexo menos representado el ejercicio de actividades autónomas. En principio, no debe considerarse que medidas como la acción positiva dirigida a alcanzar la igualdad de género en la práctica vayan en contra del principio jurídico de igualdad de trato entre hombres y mujeres.

Y se considera necesario que los cónyuges o las parejas de hecho de aquellos trabajadores autónomos que tengan acceso a un sistema de protección social deben disfrutar también del derecho a beneficiarse de protección social.

\section{MARCO LEGISLATIVO DE REFERENCIA SOBRE LA TITULARIDAD COMPARTIDA DE LAS EXPLOTACIONES AGRARIAS: LA LEY ORGÁNICA 3/2007, DE 22 DE MARZO, PARA LA IGUALDAD EFECTIVA DE MUJERES Y HOMBRES}

En el año 2007 se promulgó la Ley Orgánica 3/2007, de 22 de marzo, para la igualdad efectiva de mujeres y hombres. Esta Ley supone un avance en nuestro ordenamiento jurídico al ser un texto que pretende dar respuesta a situación real de discriminación de las mujeres. Desde un punto de vista técnico, la igualdad reconocida en el art. 14 de la Constitución española (CE) permitía su aplicación directa sin necesidad de desarrollo legislativo y, así la tutela de la igualdad y la corrección de las discriminaciones por razón de género se había venido produciendo por la jurisprudencia. Especialmente por las sentencias del Tribunal Constitucional al conocer de recursos de amparo o de cuestiones de inconstitucionalidad. Estas sentencias del Tribunal Constitucional han desarrollado el 
derecho fundamental a la igualdad y han servido de fundamento a la redacción de la LO 3/2007, que incorpora parte de esa doctrina del Tribunal Constitucional por lo que consideramos importante explicar esa jurisprudencia.

Otro fundamento importante de la LO 3/2007 son las Directivas de igualdad emanadas de la Unión Europea. Así, la Directiva 2002/73/CE, de reforma de la Directiva 76/207/CEE, relativa a la aplicación del principio de igualdad de trato entre hombres y mujeres en lo que se refiere al acceso al empleo, a la formación y a la promoción profesionales, y a las condiciones de trabajo; y la Directiva del Consejo 2004/113/CE, de 13 de diciembre, sobre aplicación del principio de igualdad de trato entre hombres y mujeres en el acceso a bienes y servicios y su suministro. Junto con estas dos, se han promulgado otras Directivas igualmente importantes, como la Directiva 2000/78/CE del Consejo, de 27 de noviembre, relativa al establecimiento de un marco general para la igualdad de trato en el empleo y la ocupación, y la Directiva 2006/54/CE del Parlamento Europeo y del Consejo de 5 de julio, relativa a la aplicación del principio de igualdad de oportunidades e igualdad de trato entre hombres y mujeres en asuntos de empleo y ocupación.

Una primera aproximación a estas Directivas, nos lleva a determinar un contenido nuclear que gravita en torno a unos puntos esenciales que son: el establecimiento de definiciones importantes, como la de discriminación directa e indirecta; el reconocimiento de las acciones positivas; la consagración de la inversión de la carga de la prueba y la promoción de organismos de igualdad.

Después se analiza el contenido material de la LO 3/2007, de 22 de marzo, para la igualdad efectiva de mujeres y hombres, que presta atención, entre otras muchas cosas, a la situación de las mujeres del medio rural. Dedicando el artículo 30 al desarrollo rural «1. A fin de hacer efectiva la igualdad entre mujeres y hombres en el sector agrario, el Ministerio de Agricultura, Pesca y Alimentación y el Ministerio de Trabajo y Asuntos Sociales desarrollarán la figura jurídica de la titularidad compartida, para que se reconozcan plenamente los derechos de las mujeres en el sector agrario, la correspondiente protección de la Seguridad Social, así como el reconocimiento de su trabajo». Esta previsión se ha desarrollado con la promulgación del Real Decreto 297/2009, de 6 de marzo, sobre titularidad compartida en las explotaciones agrarias, y la Orden ARM/2763/2009, de 5 de octubre, por la que se regula el Registro de titularidad compartida de explotaciones agrarias, derogada por la Orden AAA/1408/2012, de 26 de junio, por la que se regula el registro de explotaciones agrarias de titularidad compartida. Y, en 2011, la Ley $35 / 2011$, de 4 de octubre, sobre titularidad compartida de las explotaciones agrarias. 


\section{ESTUDIO COMPARATIVO DEL DESARROLLO EN LA NORMATIVA DE LAS COMUNIDADES AUTÓNOMAS SOBRE TITULARIDAD COMPARTIDA DE LAS EXPLOTACIONES AGRARIAS.}

En Andalucía debemos partir de la norma básica que es el Estatuto de Autonomía que, en su última redacción del 2007, incorpora en el artículo 15 la garantía de la «igualdad de oportunidades entre hombres y mujeres en todos los ámbitos». Pero en un análisis transversal del Estatuto de Autonomía andaluz la igualdad de oportunidades está presente a lo largo de todo el articulado. Y, también se preocupa el Estatuto de Autonomía del desarrollo rural.

En el año 2011, se promulgó la Orden de 12 de diciembre de 2011, de la Consejería de Agricultura y Pesca de la Junta de Andalucía, por la que se aprueba el modelo de declaración de la titularidad compartida de explotaciones agrarias para su inscripción en el registro de la titularidad compartida. (BOJA núm. 247, de 20 de diciembre de 2011). Según su Exposición de Motivos se desarrolla la previsión del artículo 30 de la LO 3/2007, de la figura jurídica de la titularidad compartida, como medida dirigida a hacer efectiva la igualdad entre mujeres y hombres en el sector agrario, y conseguir el pleno reconocimiento del trabajo de las mujeres en el ámbito rural. Y se da cumplimiento a la Ley $35 / 2011$, de 4 de octubre, sobre titularidad compartida de las explotaciones agrarias, cuyo artículo 6.1. «Para que la titularidad compartida de las explotaciones agrarias produzca todos sus efectos jurídicos será precisa su inscripción previa en el Registro constituido al efecto por la correspondiente Comunidad Autónoma».

Existe normativa de desarrollo en Aragón a través de la Orden de 7 de marzo de 2012, del Consejero de Agricultura, Ganadería y Medio Ambiente por la que se crea el Registro de titularidad compartida de explotaciones agrarias de la Comunidad Autónoma de Aragón, modificada por la Orden de 4 de junio de 2012.

En Asturias el registro se ha desarrollado en 2013 cuando se promulga el Decreto 73/2013, de 11 de septiembre, sobre registro de Explotaciones Agrarias de Titularidad Compartida del principado de Asturias, y unos meses más tarde se completa con la Resolución de 25 de septiembre de 2013, de la Consejería de Agroganadería y Recursos Autóctonos, por la que se aprueba el modelo de declaración conjunta a que se refiere el Decreto 73/2013, de 11 de septiembre, sobre Registro de explotaciones Agrarias de Titularidad Compartida del Principado de Asturias (RETICOMPA).

$\mathrm{Y}$, en las Islas Baleares, el desarrollo del Registro ha sido más reciente, en concreto en 2015, se promulga el Decreto 43/2015, de 22 de mayo, de principios generales y directrices de coordinación en materia de 
explotaciones agrarias, agrarias prioritarias, de titularidad compartida, preferentes y de ocio o autoconsumo; de regulación sobre la organización y funcionamiento del Registro Interinsular Agrario y de los registros insulares agrarios de las Illes Balears. Previamente, el artículo 13.1 de la Ley 12/2014, agraria de las Illes Balears, obligaba a otorgar la categoría de explotación de titularidad compartida a aquella que cumpla los requisitos correspondientes.

Tenemos el caso de Canarias que presentó un recurso de inconstitucionalidad contra el artículo 6 de la Ley 35/2011, de 4 de octubre, sobre titularidad compartida de las explotaciones agrarias, que se basó en cuestiones competenciales, que ha sido resuelto en la Sentencia 11/2015, de 5 de febrero de 2015, donde el TC se pronuncia sobre las competencias sobre legislación civil y ordenación general de la economía, y la constitucionalidad del precepto legal estatal que prevé la creación de un registro autonómico sobre explotaciones agrarias de titularidad compartida. Tras ser desestimado el recurso de inconstitucionalidad al declarar el TC que no se invaden competencias de las Comunidades Autónomas, finalmente se ha regulado el registro en 2016, mediante la Orden de 27 de septiembre de 2016, por la que se crea el registro de explotaciones agrarias de titularidad compartida de Canarias, que lo denomina REATC.

Cantabria no ha desarrollado el registro de titularidad compartida específicamente, sin embargo en el año 2015 ha promulgado el Decreto 42/2015, de 18 de junio, por el que se crea el Registro de Explotaciones Agrícolas de la Comunidad Autónoma de Cantabria, donde se define la titularidad compartida y en el modelo de inscripción se puede identificar la explotación como de titularidad compartida por lo que entendemos que este registro cumple las funciones, también de registro de titularidad compartida aunque se denomine de otro modo.

En Castilla-La Mancha el registro se ha desarrollado por la Orden de $13 / 10 / 2010$, de la consejería de agricultura y medio ambiente, por la que se aprueba el modelo de solicitud de comunicación titularidad compartida de explotaciones agrarias de Castilla-La Mancha (vigente hasta el 12 de julio de 2012). En 2011, se promulgó el Decreto 21/2011, de 05/04/2011, por el que se establecen disposiciones para la gestión del registro de explotaciones agrarias de Castilla-La Mancha, donde se define la titularidad compartida, y en 2012 la Orden de 29 de junio por la que se establece el régimen aplicable al Registro de Gestión de Titularidad Compartida de las Explotaciones Agrarias en Castilla-La Mancha, que deroga la Orden de 13/10/2010.

Es en el año 2012 cuando se desarrolla el registro en Castilla y León a través de la Orden AYG/546/2012, de 6 de junio, por la que se establece el procedimiento de inscripción en el Registro de titularidad compartida de las explotaciones agrarias en Castilla y León. 
En Cataluña, en la web www20.gencat.cat ${ }^{7}$ se publica la documentación a presentar y los requisitos para constituir una titularidad compartida de las explotaciones agrarias. Y su normativa reguladora es el Decreto 44/2012, de 24 de abril, por el que se crea el Sistema Integrado de datos de Explotaciones Agrarias de Cataluña y la Orden ARP/19/2017, de 8 de febrero, por la que se establece y se regula la declaración única agraria de 2017.

En Extremadura la Ley 5/1992, de 26 de diciembre, sobre Ordenación de las producciones agrarias en Extremadura, en su artículo 3, dice: «Se crea un Registro de Explotaciones Agrarias que contendrá la información necesaria que permita obtener datos fiables sobre superficies de siembra y previsiones de cosechas, ganadería y superficies destinadas al aprovechamiento directo por el ganado y otros, de modo que tanto la Administración, como los titulares de las explotaciones puedan tomar decisiones sobre los objetivos de producción en base a esta información». También, la Ley 4/1992 de 26 de noviembre, de Financiación Agraria Extremeña, en su artículo 26, apartado A) establece que para que un titular de explotación agraria pueda ser beneficiario de cualquiera de las ayudas contempladas en dicha Ley es necesario que la explotación esté inscrita y actualizada en el correspondiente Registro de Explotaciones de la propia Consejería de Agricultura y Comercio o, en su defecto, tener solicitada dicha inscripción o actualización con antelación a dicha solicitud. El Registro se creó por el DECRETO 26-1-1993, núm. 3/1993. Será en 2016 cuando se cree el registro de titularidad compartida por medio del DECRETO 106/2016, de 19 de julio, por el que se crea y regula el Registro de Titularidad Compartida de explotaciones agrarias de la Comunidad Autónoma de Extremadura.

En Galicia, en el año 2008 se promulgó el Decreto 253/2008, de 30 de octubre, por el que se crea y regula el Registro de Explotaciones Agrarias de Galicia. Ya en el año 2009, se promulgó la Orden de 22 de enero de 2009 por la que se establecen disposiciones para la gestión del Registro de Explotaciones Agrarias de Galicia. Y en 2012, el Decreto 200/2012, de 4 de octubre, por el que se regula el Registro de Explotaciones Agrarias de Galicia, que crea una nueva sección en el Registro para la titularidad compartida en cumplimiento de la Ley 35/2011.

En La Rioja, no se ha desarrollado por norma autonómica, pero en aplicación de la Ley estatal 35/2011, se ha previsto la inscripción en su web: www.larioja.org. Se establecen los requisitos de los titulares de titularidad compartida ${ }^{8}$.

7 http://web.gencat.cat/es/tramits/tramits-temes/9992_Registre-dexplotacions-agraries-de-Catalunya-de-la-titularitat-compartida? category $=7280 \mathrm{fc} 48$-a82c-11e3-a972000c29052e2c

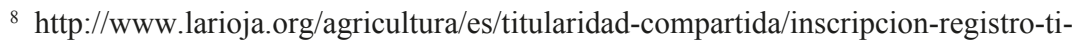
tularidad-compartida 
Madrid no ha desarrollado el Registro de titularidad compartida de las explotaciones agrarias.

En Murcia, el Decreto n. ${ }^{\circ} 448 / 2009$, de 29 de diciembre, por el que se crea y regula el Registro de Explotaciones Agrarias de la Comunidad Autónoma de la Región de Murcia, define en su artículo 2.c) la titularidad compartida, como «aquella en la que tanto la mujer como su cónyuge o persona ligada a ella con una relación de análoga afectividad inscrita en algún registro público, cumple los requisitos del artículo 4.1 de la Ley 19/1995, de 4 de julio, de Modernización de Explotaciones Agrarias y declaran tal circunstancia a la autoridad competente de la Comunidad Autónoma a los efectos de su inscripción en el Registro regulado en el artículo 5 del Real Decreto 297/2009, de 6 de marzo, sobre titularidad compartida de las explotaciones agrarias». Habiéndose regulado en 2013 el registro propio a través del Decreto n. ${ }^{\circ}$ 8/2013, de 18 de enero, por el que se crea y regula el registro de explotaciones agrarias prioritarias y de titularidad compartida de la Comunidad Autónoma de la Región de Murcia.

En Navarra, en el enlace a pie de página ${ }^{9}$, se encuentra la siguiente información sobre el procedimiento para la inscripción en el Registro de titularidad compartida de las explotaciones agrarias. Sin embargo, en cuanto a la normativa remite a la Ley 35/2011, y no se publica la norma autonómica que lo regula, ni parece que se haya publicado tampoco en su Boletín Oficial.

En el País vasco, en el año 1993 se promulgó el Decreto 84/1993, de 30 de marzo, por el que se crea y regula el Registro de Explotaciones Agrarias de la Comunidad Autónoma del País Vasco, que define la titularidad compartida. Pero no se ha desarrollado el Registro de Titularidad compartida. Sin embargo, en 2015 se promulga la Ley 8/2015, de 15 de octubre, del Estatuto de las Mujeres Agricultoras, que define la titularidad compartida y remite al registro de explotaciones agrarias del País Vasco.

En Valencia se ha regulado por la ORDEN 33/2010, de 5 de octubre, de la Conselleria de Agricultura, Pesca y Alimentación, por la que se regula el procedimiento administrativo de reconocimiento de la titularidad compartida de explotaciones agrarias en la Comunitat Valenciana y se crea un fichero de datos de carácter personal para su inscripción.

\section{ANÁLISIS DE LA LEY 35/2011, DE 4 DE OCTUBRE, SOBRE TITULARIDAD COMPARTIDA DE LAS EXPLOTACIONES AGRARIAS}

En desarrollo del artículo 30 de la LO 3/2007 se promulga la Ley 35/2011, sobre titularidad compartida de las explotaciones agrarias que incorpora a

${ }^{9} \mathrm{http} / /$ www.navarra.es/home_es/Servicios/ficha/4428/Registro-de-titularidad-compartida-de-las-explotaciones-agrarias 
nuestro ordenamiento jurídico la Directiva 2010/41/UE del Parlamento Europeo y del Consejo, de 7 de julio, sobre aplicación del principio de igualdad de trato entre hombres y mujeres que ejercen una actividad autónoma.

La Ley 35/2011 parte de la constatación de que las mujeres trabajan en las explotaciones agrarias, pero no constan como titulares de las mismas. Dos problemas básicos se plantean: la invisibilidad y la desigualdad. Con esta realidad social la titularidad compartida pretende cambiar las estructuras agrarias para que las mujeres del mundo rural gocen de una igualdad de derechos efectiva respecto de los hombres. La titularidad compartida no es sólo una nueva figura jurídica, sino que se considera una acción positiva que logre dar visibilidad a las mujeres para estas puedan ejercer y disfrutar de todos los derechos.

Para corregir esta desigualdad e invisibilidad la Ley 35/2011 propone dos modelos de visibilización del trabajo de las mujeres, un régimen de titularidad compartida de la explotación a cuya regulación dedica los artículos 4 a 8 , o la posibilidad, que prevé la disposición adicional primera, de constituir una sociedad de responsabilidad limitada entre los cónyuges o convivientes ${ }^{10}$. Además, para las personas que no se acojan al modelo de titularidad compartida, el capítulo IV de la Ley 35/2011, regula el derecho a una compensación económica, siempre que no reciban pago o contraprestación alguna por el trabajo realizado. Compensación que podía pedirse en un plazo de 5 años, tal como establece el artículo 15 de la Ley 35/2011 que regula el plazo de reclamación, de tal modo que «La acción para reclamar el pago de la compensación prescribirá a los cinco años contados desde el cumplimiento de los supuestos previstos en el artículo 13.2 de esta Ley».

En cuanto, al régimen de la titularidad compartida, con carácter general la Ley 35/2011 exige unos requisitos para ser titular de una explotación agraria. Hay que estar dado de alta en la Seguridad Social, trabajar efectivamente en la explotación y residir en el medio rural de la explotación. (art. 3).

En cuanto al régimen de funcionamiento de la explotación la Ley 35/2011 parte de un reparto equitativo tanto de responsabilidades y funciones como de beneficios. Así, se prevé una administración común de ambos titulares,

${ }^{10}$ Disposición adicional primera. Constitución de sociedades de responsabilidad limitada.

Quienes cumpliendo los requisitos previstos en el artículo 3 de la presente Ley decidan no crear una explotación agraria de titularidad compartida, podrán constituir entre sí una sociedad de responsabilidad limitada de las previstas en el artículo 5. Dos del Real Decreto-Ley 13/2010, de 3 de diciembre, de actuaciones en el ámbito fiscal, laboral y liberalizadoras para fomentar la inversión y la creación de empleo. Estas sociedades se ajustarán a los Estatutos-tipo que se aprueben por el Ministerio de Justicia, con las bonificaciones y exenciones fiscales que legalmente se determinen. 
que además responden directa, personal, solidaria e ilimitadamente de las resultas de su gestión. (art. 4). Del mismo modo que se administra y se responde conjuntamente también los beneficios se reparten al 50 por ciento entre ambos titulares. (art. 5).

Ahora bien, para que se aplique este régimen jurídico la Ley 35/2011 exige la inscripción en un registro constituido al efecto en la correspondiente Comunidad Autónoma. (art. 6.1) ${ }^{11}$.

En la declaración conjunta se debe identificar tanto los titulares como la explotación, y los bienes que la integran, y entre otros datos económicos y fiscales, es importante que se acredite el vínculo entre los titulares que se puede hacer presentando el certificado de matrimonio o de la inscripción como pareja de hecho, o, en los casos de mera convivencia incluir en la declaración la aseveración de que existe una análoga relación de afectividad. (art. 6.2).

La Ley 35/2011 regula también el régimen de extinción de la titularidad compartida que se regula en el artículo 8.

En cuanto al régimen fiscal el artículo 9 de la Ley 35/2011, establece que la titularidad compartida de explotaciones agrarias tendrá la consideración a efectos tributarios, de entidad del artículo 35.4 de la Ley 58/2003, de 17 de diciembre, General Tributaria. Este artículo 35.4 regula que «Tendrán la consideración de obligados tributarios, en las Leyes en que así se establezca, las herencias yacentes, comunidades de bienes y demás entidades que, carentes de personalidad jurídica, constituyan una unidad económica o un patrimonio separado susceptibles de imposición». De tal modo que cada titularidad compartida debe tributar y tendrá un número de identificación fiscal para sus relaciones de naturaleza o con trascendencia tributaria. Este número de identificación fiscal será facilitado por la Administración General del Estado, de oficio o a instancia de la persona interesada.

${ }^{11}$ El documento que se inscribe es una declaración conjunta en la que hagan constar lo siguiente:

a) Datos de identificación personal.

b) Datos de identificación de la explotación.

c) Datos de los bienes y derechos que conforman la explotación agraria de titularidad compartida. En particular, en el caso de bienes inmuebles y de derechos reales sobre los mismos, se deberá especificar la referencia catastral y cualesquiera otros datos que pudieran resultar de la normativa vigente.

d) Número de Identificación Fiscal asignado por la Administración tributaria competente conforme al artículo 9 de esta Ley.

e) Datos identificativos de la cuenta bancaria asociada a la titularidad compartida.

f) Datos identificativos del representante, en su caso, de la titularidad compartida.

g) Certificado de matrimonio o certificado de inscripción de pareja de hecho, o aseveración de vinculación de análoga relación de afectividad incluida en la declaración conjunta. 
En materia de Seguridad Social, el artículo 10 de la Ley 35/2011, establece que los titulares de la explotación de titularidad compartida que realicen una actividad agraria se incluirán en el sistema de la Seguridad Social.

Hemos hablado antes del reparto de responsabilidades y beneficios, el artículo 11 de la Ley 35/2011 establece un reparto por mitades iguales para cada cónyuge o miembro de la pareja de hecho titulares de la explotación en régimen de titularidad compartida. Este reparto por mitad se prevé para: Subvenciones, Ayudas directas y Ayudas de desarrollo rural. Ya procedan, estas subvenciones o ayudas, de fuentes de financiación europeas, estatales o autonómicas. Pero para las subvenciones estatales se establece un trato preferente en el art. 12. 3. «Las bases reguladoras de subvenciones financiadas por la Administración General del Estado, incorporarán para beneficiar a las explotaciones agrarias de titularidad compartida un trato preferente. Dicho trato preferente consistirá, a igualdad de requisitos para las explotaciones y para cada nivel de apoyo, en el incremento de la ponderación o puntuación en los criterios objetivos de otorgamiento de subvenciones y ayudas públicas establecidas en las referidas bases reguladoras, adicionalmente a otras situaciones de preferencia y prioridad establecidas en el resto del ordenamiento jurídico».

La solicitud de las citadas ayudas se realizará a nombre de la entidad de titularidad compartida que constituye la explotación agraria de titularidad compartida, efectuándose el pago correspondiente en la cuenta bancaria asociada a la titularidad compartida.

La Ley 35/2011, en su artículo 12, establece que el Ministerio de Medio Ambiente, y Medio Rural y Marino adoptará medidas para fomentar la constitución de explotaciones agrarias de titularidad compartida. Y estas explotaciones tendrán la consideración de prioritarias a los efectos de la Ley 19/1995, de Modernización de las explotaciones agrarias, aunque para tener la consideración de prioritarias hay que cumplir unos requisitos.

En cuanto a la compensación económica por razón de colaboración efectiva en la explotación agraria. El art. 13.1 de la Ley 35/2011 prevé que «Las personas casadas o unidas por análoga relación de afectividad que participen de manera efectiva y regular en la actividad agraria de la explotación, que no reciban pago o contraprestación alguna por el trabajo realizado ni se hayan acogido al régimen de titularidad compartida previsto en la presente Ley, tendrán derecho a una compensación económica».

La cuantía de la compensación dependerá del valor real de la explotación agraria, y se calculará en función del tiempo real y efectivo dedicado a la explotación. (art. 14). Estableciéndose un plazo para reclamar esta compensación de 5 años (art. 15).

La opción del modelo de sociedad de responsabilidad limitada, está prevista en la Disposición adicional primera de la Ley 35/2011, para «quienes cumpliendo los requisitos previstos en el artículo 3 de la presente Ley 
decidan no crear una explotación agraria de titularidad compartida». En estos casos «podrán constituir entre sí una sociedad de responsabilidad limitada de las previstas en el artículo 5. Dos ${ }^{12}$ del Real Decreto-Ley 13/2010, de 3 de diciembre, de actuaciones en el ámbito fiscal, laboral y liberalizadoras para fomentar la inversión y la creación de empleo. Estas sociedades se ajustarán a los Estatutos-tipo que se aprueben por el Ministerio de Justicia, con las bonificaciones y exenciones fiscales que legalmente se determinen».

El objetivo de este Real Decreto-Ley 13/2010 es «continuar y reforzar la política de impulso al crecimiento de la economía española y al incremento de su competitividad través de medidas de apoyo a la actividad empresarial, esencialmente enfocadas a las pequeñas y medianas empresas, de tal modo que, a través de una reducción de cargas impositivas y de otra índole, se favorezca la inversión productiva, la competitividad de las empresas españolas y, por ende, la creación de empleo».

La aplicación del art. 5.dos supone una simplificación en los trámites de constitución de las sociedades mercantiles de responsabilidad limitada, que son un modelo de organización empresarial con personalidad jurídica propia lo que les permite actuar válidamente en el tráfico jurídico, pero con una responsabilidad limitada al capital de la sociedad, y por lo que respecta a las explotaciones agrarias esa sociedad se constituiría por los dos titulares cónyuges o convivientes.

Así, las soluciones que regula la Ley 35/2011, sobre titularidad compartida de las explotaciones agrarias son tres:

1. La titularidad compartida de la explotación agraria: Un modelo de visibilización del trabajo de las mujeres, un régimen de titularidad compartida de la explotación, a cuya regulación dedica los artículos 4 a 8.

${ }^{12}$ Artículo 5. Medidas para agilizar y simplificar la constitución de sociedades mercantiles de capital.

Dos. No obstante lo dispuesto en el apartado anterior, cuando el capital social de las sociedades de responsabilidad limitada no sea superior a 3.100 euros y sus estatutos se adapten a algunos de los aprobados por el Ministerio de Justicia, se seguirán las reglas previstas en el mismo con las siguientes especialidades:

a) El notario otorgará la escritura de constitución en el mismo día en el que, aportados todos los antecedentes necesarios para ello, reciba la certificación negativa de denominación expedida por el Registro Mercantil Central.

b) El registrador mercantil procederá a la calificación e inscripción dentro del plazo de las 7 horas hábiles siguientes a la recepción telemática de la escritura, entendiéndose por horas hábiles a estos efectos las que queden comprendidas dentro del horario de apertura fijado para los registros.

c) Se aplicarán como aranceles notariales y registrales la cantidad fija de 60 euros para el notario y 40 para el registrador. 
2. La constitución de una sociedad de responsabilidad limitada: La posibilidad, que prevé la disposición adicional primera, de constituir una sociedad de responsabilidad limitada entre los cónyuges o convivientes.

3. El derecho a una compensación económica: Para quienes no se acojan al modelo de titularidad compartida, el capítulo IV de la Ley 35/2011, regula el derecho a una compensación económica, siempre que no reciban pago o contraprestación alguna por el trabajo realizado.

\section{ANÁLISIS DE DERECHO COMPARADO SOBRE IGUALDAD Y EXPLOTACIONES AGRARIAS: FRANCIA E ITALIA}

En Francia, destaca la figura del estatuto del cónyuge colaborador. Francia modificó su Constitución al adoptar la Ley Constitucional no 99-569, de 8 de julio de 1999 relativa a la igualdad entre mujeres y hombres (J.O., 9 de julio de 1999); así como la Ley n ${ }^{\circ} 2000-493$ de 6 de junio de 2000 que tiende a favorecer el igual acceso de las mujeres y de los hombres a los mandatos electorales y a las funciones electivas ${ }^{13}$.

En 1999, se promulgó la Ley francesa de orientación Agrícola, de 9 de julio, que incorpora el reconocimiento del carácter multifuncional de la agricultura, donde ya no sólo se van a producir alimentos, sino que debe existir una preocupación por el medio ambiente. Así, el artículo 1 de la Ley de Orientación Agrícola de Francia establece que la política agraria debe tener en cuenta la función económica, pero también, medioambiental y social de la agricultura. A esta plurifuncionalidad inherente al mundo rural, se refiere también, el Dictamen del Comité Económico y Social sobre «El papel de la mujer rural en el desarrollo sostenible de la agricultura de la Unión Europea», (2000/C 204/07). Y, este principio de multifuncionalidad de la agricultura se incorporó, también, a la Agenda 2000 aprobada en el Consejo Europeo de Berlín, como principio rector del segundo pilar de la futura política agraria europea.

La Ley de Orientación Agrícola (LOA) de 9 de julio de 1999, creó los Contratos Territoriales de Explotación (CTE), con la finalidad de incentivar a los agricultores para adoptar los cambios en las explotaciones para su modernización o multifuncionalidad de la agricultura. Con un contrato territorial de explotación, el agricultor tiene que cumplir una serie de medidas de mejora, a nivel de productividad de la explotación, de cuidar el medio ambiente, es decir, cuidar los aspectos ecológicos, y, desde un punto de vista

13 Serra Cristóbal 2008: 170. Y Mertens De Wilmars y Cantarino, «Ciudadanía paritaria ¿Una cuestión de concepto?, en http://www.ub.edu/demoment/jornadasfp/PDFs/30Ciudadania\%20paritaria.pdf 
social, se fomenta la creación y/o mantenimiento de empleo, la legalización de economía sumergida, y la mejora de las condiciones laborales. Con la finalidad última de la modernización de la agricultura francesa.

Este modelo francés de contrato territorial se recepciona en España, a través de la Ley 45/2007, cuyo artículo 16.2 establece que «El contrato territorial es el instrumento que establece el conjunto de compromisos a suscribir entre las Administraciones Públicas y los titulares de las explotaciones agrarias que orienten e incentiven su actividad en beneficio de un desarrollo sostenible del medio rural. La suscripción de estos contratos será requisito necesario para beneficiarse de las prioridades señaladas en el apartado anterior, y sus determinaciones se ajustarán a las Directrices Estratégicas Territoriales de Ordenación Rural. El resto de sus requisitos, condiciones y efectos se determinarán reglamentariamente». Y este Reglamento se promulgó por el Real Decreto 1336/2011, de 3 de octubre, por el que se regula el contrato territorial como instrumento para promover el desarrollo sostenible del medio rural.

Ley de orientación agraria francesa de 9 de julio de 1999 incluyó como novedad el Estatuto del cónyuge colaborador de modo que el/la cónyuge pueda optar por ser colaborador o colaboradora, siempre y cuando, la explotación no esté constituida como sociedad. De este modo el/la cónyuge se beneficia del llamado seguro de vejez de personas no asalariadas. Se establece que el cónyuge del titular de una explotación puede trabajar como colaborador de la explotación.

La Ley de Orientación agraria francesa de 9 de julio de 1999 incluye como una de sus novedades la regulación del Estatuto del cónyuge del agricultor. La Ley de Orientación A de 1999 introdujo dos innovaciones para el estatuto del cónyuge del agricultor:

- la creación de un estatuto de colaborador de la explotación

- y la institución de un derecho de crédito de salaire diffèrè en beneficio del cónyuge del agricultor.

Considera la doctrina que esta previsión constituye una cierta respuesta a la reivindicación de las mujeres de los agricultores que desarrollaban su trabajo con ellos en la explotación y, sin embargo, no han visto reconocido un verdadero estatuto profesional como consecuencia de la actividad realmente desplegada. Se configura como un derecho de crédito reconocido al cónyuge del agricultor que no ha sido remunerado por la actividad desarrollada en la explotación. No tiene carácter obligatorio y supone una opción de la persona interesada. «El cónyuge del titular de una explotación o de una empresa agraria que no está constituida bajo la forma de una sociedad o de una cotitularidad entre cónyuges puede ejercer su actividad 
profesional en calidad de colaborador de la explotación o de la empresa agraria» ${ }^{14}$.

En cuanto a Italia, la Constitución italiana de 1948, reconoce la igualdad en el artículo 3 que establece que todos los ciudadanos tienen igual dignidad social y son iguales ante la ley, sin distinción por razón de sexo, raza, lengua, religión, opinión política, o condiciones personales o sociales. Compite a la República remover los obstáculos de orden económico y social que limitan de hecho la libertad y la igualdad de los ciudadanos, impidiendo el pleno desarrollo de la persona humana y la efectiva participación de todos los trabajadores en la organización política, económica y social del País.

Si comparamos este artículo con la regulación de nuestra Constitución, vemos que se correspondería con nuestro artículo 14 , donde se establece la igualdad ante la ley, y la no discriminación por razón de sexo, pero también, con nuestro artículo 9.2 donde se establece la obligación de los poderes públicos de remover los obstáculos para que la libertad y la igualdad sean reales y efectivas. Lo que ya hemos analizado como el reconocimiento de la igualdad formal y la igualdad material.

Pero la Constitución italiana de 1948 incorpora, además, un artículo específico reconociendo derechos para la mujer trabajadora. El artículo 37 de la Constitución italiana establece que la mujer trabajadora tiene los mismos derechos, y la paridad en el trabajo, la misma retribución de los trabajadores. Y, además, como medida de conciliación de la vida familiar y laboral, se establece que las condiciones de su trabajo deben consentir el desarrollo de sus funciones familiares y asegurar a la madre y al hijo una especial y adecuada protección.

Con éste marco jurídico constitucional, la no discriminación por razón de sexo, se desarrolla en normas de rango legal. En 1977, se promulgó la Ley de 9 de diciembre, núm. 903, de igualdad de trato entre hombres y mujeres en materia de trabajo. Su artículo 1 prohíbe cualquier discriminación por razón de sexo en el acceso al trabajo, ya sea por razones de estado matrimonial, de familia o de embarazo. E, incluso, prohíbe la discriminación indirecta, a través de mecanismos de preselección o a través de publicidad que exijan como requisito profesional la pertenencia a uno $u$ otro sexo. Aunque, esta Ley de 1977 no define que sea discriminación indirecta, cosa que ocurre ya en la Ley 125/1991, que estudiamos a continuación. Lo que reconoce el artículo 2 de ésta Ley de 1977 es un derecho de las trabajadoras a la igualdad de retribución ante prestaciones iguales. En España hubo que esperar hasta el año 2002, para que se reformara el Estatuto de los Trabajadores por la Ley $33 / 2002$, introduciendo esta igualdad de remuneración por razón de sexo.

${ }^{14}$ Muñiz Espada 2002: 6-10, en https://www.nodo50.org/mujeresred/rural_pdf/experiencias.pdf 
En 1991, se promulgó en Italia la Ley 125/1991, sobre acciones positivas para la realización de la paridad hombre-mujer en el trabajo. La finalidad de esta Ley 125/1991, según su artículo 1, es favorecer la ocupación femenina, y alcanzar la igualdad en el trabajo entre el hombre y la mujer, mediante la adopción de acciones positivas que remuevan los obstáculos que impiden la igualdad de oportunidades. Y, en concreto, favorecer el acceso al trabajo autónomo, y favorecer el acceso a los sectores profesionales donde las mujeres están subrepresentadas.

Otro elemento importante de la Ley 125/1991, es la creación del Comité Nacional para la aplicación del principio de igualdad de trato e igualdad de oportunidades entre trabajadores y trabajadoras. Según el artículo 5.1 de la Ley 125/1991, el Comité se constituye en el Ministerio de Trabajo y de la Seguridad Social, con la finalidad de promover la remoción de los comportamientos discriminatorios por razón de sexo y de los obstáculos que limitan de facto la igualdad de la mujer en el acceso al trabajo y en la carrera profesional.

En 1992, se promulga la Ley de 25 de febrero de 1992, núm. 125, de acciones positivas para las mujeres empresarias. Su finalidad, según el artículo 1, es promover la igualdad sustancial entre hombres y mujeres en la actividad económica y empresarial. En concreto, favorecer a las mujeres empresarias, promover su formación, facilitarles el acceso al crédito, incentivar la presencia de las mujeres en las empresas familiares, y favorecer su incorporación a los sectores productivos más innovadores.

Se establecen en el artículo 2.1.a) de ésta Ley 215/1992, una serie de beneficios de los que pueden ser beneficiarias las mujeres para el desarrollo de la actividad empresarial en diversos sectores, entre los que se encuentra la agricultura. De tal modo que, aunque no es una Ley específica para la mujer rural, sí prevé ayudas para las mujeres empresarias en éste sector. La importancia del sector agrícola se deja sentir en la inclusión del Ministro de Agricultura en el Comité de mujeres empresarias.

En el año 2000, se publica la Ley de 8 de marzo, núm. 53, de disposiciones para el apoyo a la maternidad y a la paternidad, para el derecho al cuidado y a la formación y para la coordinación del tiempo de la ciudad. Su finalidad esencial es promover el equilibrio entre el tiempo de trabajo y de cuidado, y la formación, a través de la licencia parental y la ampliación del apoyo a los padres de minusválidos. Así como, las licencias para la formación y educación continua. Aunque no existe una regulación específica para las mujeres rurales, sin duda, ésta Ley les será de aplicación. De hecho, el artículo 25 prevé que los Alcaldes constituyan una Mesa de concertación para la aplicación y verificación de los proyectos contenidos en el plan de horarios. Esa mesa se integra por un conjunto de miembros, entre los que deben estar representantes de los empresarios de grandes, medianas y pequeñas empresas, comercio, servicios, artesanía y agricultura. 
Pero será en el año 2005 cuando se promulgue la Ley italiana de 28 de noviembre, cuyo artículo 6 delega en el Gobierno italiano la elaboración de un Decreto Legislativo para el reordenamiento de las disposiciones vigentes en materia de igualdad de oportunidades entre el hombre y la mujer. Dando lugar en el año 2006, a la promulgación del Código de la igualdad de oportunidades entre hombre y mujer, a través del Decreto Legislativo de 11 de abril de 2006, núm. 198. El artículo 40 se dedica a la carga de la prueba, en los mismos términos de la Ley 125/1991.

Para la actividad agrícola se establece una regulación específica en el artículo 63 del Código de igualdad de oportunidades, pero dentro de la regulación de la protección de la maternidad y de la paternidad. Así, establece este artículo 63 el derecho a las prestaciones por maternidad y paternidad de los trabajadores y las trabajadoras agrícolas. Para lo que han debido estar inscritos como trabajadores y trabajadoras agrícolas al menos 51 días en el año precedente.

Sin embargo, éste Código de la igualdad de oportunidades entre hombre y mujer, no ha previsto una regulación específica para la mujer rural, en el sentido de promover sus derechos como ciudadana y profesional. De tal modo que no encontramos, hasta ahora en el ordenamiento italiano, la figura de la titularidad compartida de las explotaciones agrarias.

Más recientemente, en el año 2010 se promulgó el Decreto Legislativo núm. 5, de 25 de enero, de aplicación de la Directiva 2006/54/CE, relativa a la aplicación del principio de igualdad de oportunidades e igualdad de trato entre hombres y mujeres en asuntos de empleo y ocupación. Este Decreto de 25 de enero de 2010, no contiene disposiciones relativas a la agricultura o a las mujeres rurales y, por lo tanto, no incorpora la figura de la titularidad compartida de las explotaciones agrarias.

\section{LA TITULARIDAD COMPARTIDA COMO MEDIDA «BIDIRECCIONAL»}

El concepto de medida bidireccional ha sido utilizado por el Tribunal Constitucional, ya en una temprana sentencia en 1992, en la STC 229/1992, que conoce de un recurso de amparo planteado por una trabajadora de la minería frente a la decisión empresarial de no contratarla, aún habiendo superado las pruebas pertinentes y haber sido declarada apta para el puesto de ayudante minero al igual que sus compañeros varones, argumentando la vulneración del art. $14 \mathrm{CE}$ ya que el único motivo de la no contratación es su condición de mujer.

En primera instancia la Magistratura de Trabajo núm. 2 de Oviedo declaró la no vulneración del art. $14 \mathrm{CE}$ argumentando que la prohibición de trabajar en el interior de la mina para las mujeres se ampara en normas internacionales. Confirmándose en suplicación por el TSJ Madrid. 
Contra esta última sentencia se interpone recurso de amparo ante el TC argumentando que la normativa preconstitucional protectora de la mujer ha quedado derogada por la Constitución de 1978.

El TC otorga el amparo y argumenta en el FJ 2 que «A diferencia del principio genérico de igualdad que no postula ni como fin ni como medio la paridad y sólo exige la razonabilidad de la diferencia normativa de trato, la prohibición de discriminación entre los sexos implica un juicio de irrazonabilidad de diferenciación establecido ya ex Constitutione que impone como fin y generalmente como medio la parificación, de modo que la distinción entre los sexos sólo puede ser utilizada excepcionalmente como criterio de diferenciación jurídica de trato entre los varones y las mujeres también en materia de empleo» (STC 229/1992, FJ 2).

Seguidamente el TC afirma el «carácter bidireccional» de la regla de parificación entre los sexos, aunque esta bidireccionalidad no debe impedir ver que las mujeres han venido sufriendo una discriminación histórica por lo que en conexión con el 9.2 CE la interdicción de la discriminación implica medidas que aseguren la igualdad efectiva. Lo que permite establecer un «derecho desigual igualatorio», es decir, «la adopción de medidas reequilibradoras de situaciones sociales discriminatorias preexistentes para lograr una sustancial y efectiva equiparación entre las mujeres, socialmente desfavorecidas, y los hombres, para asegurar el goce efectivo del derecho a la igualdad por parte de la mujer» (STC 229/1992, FJ 2). Concluyendo el TC que la «prohibición de trabajar en el interior de las minas a la mujer, aunque responda históricamente a una finalidad protectora, no puede ser calificada como una medida de acción positiva o de apoyo o ventaja para conseguir una igualdad real de oportunidades, ya que no favorece a ésta, sino que más bien la restringe al impedir a la mujer acceder a determinados empleos» (STC 229/1992, FJ 2 in fine).

Será en la STC 12/2008, donde el TC utilice el concepto de bidireccionalidad al considerar que las cuotas electorales introducidas en la LOREG por la LOIMH producen ese efecto. Como sabemos la LOIMH introduce el art. 44 bis en la LOREG estableciendo que en las listas electorales deben figurar candidatos de uno y otro sexo en una proporción del 40-60. De tal modo que deben incluirse un mínimo del 40 por ciento de hombres o un mínimo del 40 por ciento de mujeres hasta un máximo del 60 por ciento. Esta medida incluida en nuestro ordenamiento por la LOIMH persigue como medida de acción positiva alcanzar una presencia equilibrada de mujeres y hombres en la representación política una vez constatada la baja presencia de mujeres en el parlamento. Pero, como apunta el TC, la medida se formula garantizando también un mínimo de hombres lo que la convierte en una medida de acción positiva en favor de las mujeres pero que permite finalmente el equilibrio entre sexos, no excluyendo totalmente a los hombres. En 
el fundamento jurídico 3 de la STC 12/2008 se establece que «Dicha reforma legislativa, incorporada por la disposición adicional segunda LOIHM, pretendiendo la igual participación efectiva de hombres y mujeres en la integración de las instituciones representativas de una sociedad democrática, no establece una medida de discriminación inversa o compensatoria (favoreciendo a un sexo sobre otro), sino una fórmula de equilibrio entre sexos, que tampoco es estrictamente paritaria, en cuanto que no impone una total igualdad entre hombres y mujeres, sino la regla de que unos y otras no podrán integrar las candidaturas electorales en una proporción inferior al 40 por 100 (o lo que es lo mismo, superior al 60 por 100). Su efecto, pues es bidireccional, (negrita del TC) en cuanto que esa proporción se asegura igualmente a uno y otro sexo.» ${ }^{15}$ La medida es proporcionada y razonable (FJ 11). A este respecto, considera la doctrina, que «la razonabilidad y la proporcionalidad se encuentran en que ese porcentaje, al ser superior al 40, también puede beneficiar al hombre, en la medida en que el porcentaje de 60-40 no es de atribución específica ni al hombre ni a la mujer» ${ }^{16}$. Efectivamente, no hay un tratamiento jurídico diferente entre hombres y mujeres, por lo que no habría que acudir al concepto de acción positiva para justificar la constitucionalidad de la medida ${ }^{17}$. «Las personas de ambos géneros se encuentran en iguales condiciones de ser incluidas en las candidaturas porque ningún individuo se halla en una situación más favorable o desfavorable en virtud de su sexo. Esto permite concluir que la medida no es constitucional porque la diferenciación sea razonable, sino, de manera más sencilla, porque no existe diferenciación ${ }^{18}$. Se ha considerado, también, que no es una medida de discriminación inversa o compensatoria a favor de la mujer, «sino, el equilibrio entre sexos que no es exactamente paritario pues se establece una horquilla

${ }^{15}$ Llama la atención, $\mathrm{M}^{\mathrm{a}}$ Luz MARTÍNEZ, sobre que el TC nada dice sobre su posible vigencia provisional, probablemente, razona la autora, «como consecuencia de la naturaleza jurídica que atribuye a estos porcentajes, a los que se refiere como $<<$ una fórmula de equilibrio de sexos, que tampoco es estrictamente paritaria $>>$ », cfr. Martínez Alarcón 2008: 120.

${ }^{16}$ Cfr. Balaguer Callejón: 168.

17 Considera $\mathrm{M}^{\mathrm{a}}$ del Pilar Molero que esto es cierto, la medida no favorece al hombre ni a la mujer, pero con fundamento en la propia Exposición de Motivos de la LOIMH entiende que «la cuota mínima se reserva para la mujer, pues es el sexo que hasta ahora ha contado con menor representación». Cfr. Martín-Salas 2011: 95.

http://historico.juridicas.unam.mx/publica/librev/rev/qdiuris/cont/15/cnt/cnt6.pdf

18 Cfr. Biglino Campos 2008: 286. Este argumento ya lo desarrolló la autora en 2005 al analizar la constitucionalidad de las listas paritarias. Cfr. «Acerca de la constitucionalidad de las leyes electorales paritarias», en XXV Aniversario de la Constitución Española. Propuestas de reforma, Centro de Ediciones de la Diputación Provincial de Málaga CEDMA, Málaga, 2005, p. 364. 
entre el $40 \%$ y el $60 \%$ a la hora de que unos y otras integren las candidaturas electorales ${ }^{19}$.

En cuanto a la naturaleza jurídica de esta medida, ha considerado la doctrina que esta formulación «aparentemente neutra» no puede hacer olvidar su finalidad, que es compensar una situación histórica de desigualdad de las mujeres en el acceso a la representación, y por ello se ha afirmado que la paridad electoral «está mucho más cerca de una medida de reserve discrimination que de cualquier otra cosa» ${ }^{20}$. Contrariamente, se ha considerado que no estamos ante una medida de acción positiva sino ante una medida «antidiscriminatoria, destinada a remover una discriminación indirecta, en virtud de la cual la presencia de mujeres en órganos representativos sigue siendo escasa ${ }^{21}$. Las cuotas mínimas no se consideraría medida de acción positiva porque «más que mejorar la posición de partida de las mujeres», imponen un resultado 22 .

Sobre los sistemas electorales y la representación política femenina se ha razonado por la doctrina que una representación integradora tiene mayor legitimidad que una representación excluyente. En este sentido los sistemas, «serán tanto más legítimos cuanto mayor sea el grado de integración que consigan ${ }^{23}$.

Este concepto se reitera en la STC 13/2009, donde igualmente considera el TC el carácter bidireccional de las cuotas electorales de la Ley del

${ }^{19}$ Cfr. Figueruelo Burrieza 2008: 226. Analiza esta autora la realidad social de las candidaturas electorales desde la entrada en vigor de la CE de 1978, constatando que «han sido muy excepcionales los casos en los que las mujeres ocupaban el $40 \%$ de una lista electoral.» Y concluye que por esta evidente realidad «sí podemos sostener que nos hallamos ante una medida de acción positiva en el marco de una legislación que pretende superar una realidad social que se caracteriza por la menor presencia de la mujer en la política y en las instituciones públicas». Cfr. Ibídem: 226.

${ }^{20}$ En este sentido, Martínez Alarcón 2008: 609.

${ }^{21}$ Esta es la opinión de Paloma Biglino Campos, «Variaciones sobre las listas electorales...», cit., pp. 286-287. Y «Acerca de la constitucionalidad...», cit., p. 364.

${ }^{22}$ Blanca Rodríguez Ruíz y Ruth Rubio Marín, «De la paridad, la igualdad y la representación en el estado democrático», Revista Española de Derecho Constitucional, núm. 81, septiembre-diciembre (2007), p. 131.

${ }^{23}$ Cfr. Teresa Freixes Sanjuán, «El impacto de los sistemas electorales en la representación política femenina y la introducción de medidas de acción positiva en la legislación electoral», en Estudios de Teoría del Estado y Derecho Constitucional en honor de Pablo Lucas Verdú, (dirs.) Raúl Morodo y Pedro de Vega, Servicio de publicaciones de la Facultad de Derecho de la Universidad Complutense, Madrid, 2001, p. 1637. Antes de la reforma de la LOREG por la LOIMH, razonaba la autora sobre la constitucionalidad de las medidas de acción positiva consistentes en la posibilidad de reforma de la ley electoral. Apuesta por la constitucionalidad de las medidas confirmada por la Sentencia 12/2008. Ibidem, p. 1659. 
Parlamento Vasco 4/2005, que establece una composición equilibrada en las listas electorales del 50 por ciento. En el fundamento jurídico 11 se afirma el «carácter bidireccional de la regla de parificación entre sexos».

Consideramos que este concepto de bidireccionalidad es aplicable a la titularidad compartida de las explotaciones agrarias, concebida originariamente como una medida de acción positiva, según la propia Exposición de Motivos de la Ley, que pretende visibilizar el trabajo de las mujeres, su redacción es neutral o si se quiere sus efectos son bidireccionales ya que se permite acceder a la titularidad de las explotaciones agrarias al cónyuge trabajador sin diferenciar entre hombres y mujeres de tal modo que la persona, hombre o mujer, cónyuge o pareja de hecho del titular, que trabaja en la explotación puede acceder a su titularidad. Este efecto bidireccional creemos que permite cumplir con la proporcionalidad exigible para la legitimidad de las medidas de acción positiva en la medida en que preverlo sólo para las mujeres dejaría fuera a los hombres que no son titulares de la explotación de su pareja lo que supondría un perjuicio no amparable por la norma ni por la idea de equidad o equiparación entre sexos. Esta exigencia de proporcionalidad se formula en el art. 11 de la $\mathrm{LOIHM}^{24}$.

\section{CONCLUSIONES}

Primera: La finalidad de la institución de la titularidad compartida pretende acabar con la invisibilidad del trabajo de las mujeres en el mundo rural. En la mayoría de los casos, el titular de la explotación agraria era el marido o la pareja de hecho varón, y así, el trabajo desarrollado por las mujeres quedaba fuera de la realidad jurídica. En otras palabras, en el ámbito de la explotación familiar del medio rural, son muchas las mujeres que comparten con los hombres las tareas agrarias, asumiendo buena parte de las mismas y aportando tanto bienes como trabajo. Sin embargo, en la mayoría de los casos, figura sólo el hombre como titular de la explotación agraria, lo que dificulta que se valore adecuadamente la participación de la mujer en los derechos y obligaciones derivados de la gestión de dicha explotación, en condiciones de igualdad.

${ }^{24}$ Artículo 11. Acciones positivas.

1. Con el fin de hacer efectivo el derecho constitucional de la igualdad, los Poderes Públicos adoptarán medidas específicas en favor de las mujeres para corregir situaciones patentes de desigualdad de hecho respecto de los hombres. Tales medidas, que serán aplicables en tanto subsistan dichas situaciones, habrán de ser razonables y proporcionadas en relación con el objetivo perseguido en cada caso.

2. También las personas físicas y jurídicas privadas podrán adoptar este tipo de medidas en los términos establecidos en la presente Ley. 
Segunda: Consideramos que la titularidad compartida pretende conseguir empoderamiento de las mujeres, visibilización, participación y reconocimiento de derechos. La titularidad compartida pretende cambiar las estructuras agrarias para que las mujeres del mundo rural gocen de una igualdad de derechos efectiva respecto de los hombres. Como afirma la LO de igualdad, en su artículo 30: «para que se reconozcan plenamente los derechos de las mujeres en el sector agrario, la correspondiente protección de la Seguridad Social, así como el reconocimiento de su trabajo».

Tercera: Para nosotros la regulación de la titularidad compartida de las explotaciones agrarias tiene un efecto bidireccional al permitir el acceso a la titularidad de las explotaciones tanto a los hombres como a las mujeres trabajadores de la misma y cónyuge o pareja de hecho del titular. Bidireccionalidad que conecta con la idea de equidad y equiparación entre sexos y que satisface el requisito de proporcionalidad de las medidas de acción positiva.

\section{BIBLIOGRAFÍA}

Balaguer Callejón, M. L. Mujer y Constitución, Ediciones Cátedra, (Madrid, 2005). _Igualdad y Constitución Española, Tecnos, (Madrid, 2010).

Biglino CAMPOS, P. «Acerca de la constitucionalidad de las leyes electorales paritarias», en XXV Aniversario de la Constitución Española. Propuestas de reforma, Centro de Ediciones de la Diputación Provincial de Málaga CEDMA, (Málaga, 2005): 359-370.

— «Variaciones sobre las listas electorales de composición equilibrada (Comentario a la STC 12/2008)», Revista Española de Derecho Constitucional, núm. 83, (mayo agosto 2008): 277-299.

De Miguel, A. Neoliberalismo sexual. El mito de la libre elección, Ediciones Cátedra, (Madrid, 2015).

Figueruelo BurriezA, Á. «Representación política y democracia paritaria (A propósito de la Sentencia del TC 12/2008, de 29 de enero)», Revista Europea de Derechos Fundamentales, núm. 12, (2ºmestre 2008): 211-233.

FREIXES SANJUÁn, T. «La igualdad entre mujeres y hombres en el proceso de integración europea», en Mujer y Constitución en España, Centro de Estudios Políticos y Constitucionales, (Madrid, 2000): 43-79.

«El impacto de los sistemas electorales en la representación política femenina y la introducción de medidas de acción positiva en la legislación electoral», en Estudios de Teoría del Estado y Derecho Constitucional en honor de Pablo Lucas Verdú, (dirs.) Raúl Morodo y Pedro de Vega, Servicio de publicaciones de la Facultad de Derecho de la Universidad Complutense, (Madrid, 2001): 1631-1661.

Mackinnon, C. A. Hacia una teoría feminista del Estado, Ediciones Cátedra, Madrid, 1995.

Martínez Alarcón, M. ${ }^{a}$ L., «Comentario a la Sentencia del Tribunal Constitucional 12/2008, de 29 de enero, sobre la Ley Orgánica para la Igualdad efectiva entre mujeres y hombres», Teoría y Realidad Constitucional, núm. 22, (2008): 605-624. 
—LLa Ley Orgánica para la igualdad efectiva de mujeres y hombres y la sentencia del Tribunal Constitucional 12/2008, de 29 de enero», Revista de Estudios Politicos (Nueva época), núm. 142, Madrid, octubre-diciembre (2008): 105-137.

Mertens de Wilmars, F. y Cantarino, E. «Ciudadanía paritaria ¿Una cuestión de concepto?, en http://www.ub.edu/demoment/jornadasfp/PDFs/30-Ciudadania\%20paritaria.pdf

Molero Martín-SAlas, M. ${ }^{a}$ Del Pilar, «Comentario a la Sentencia del Tribunal Constitucional español 12/2008, de 29 de enero», en quid iuris, núm. 15, (2011): 89-102.

Monereo Atienza, C. Desigualdades de género y capacidades humanas, Editorial Comares, (Granada, 2010).

MuÑIZ EsPADA, E. «Relaciones entre las experiencias agrarias y el mundo rural a través de la actividad de las mujeres», en Jornada Temática sobre Políticas de relevo generacional e incorporación de la mujer al mundo rural, (Madrid, 14 de noviembre de 2002): 6-10, en https://www.nodo50.org/mujeresred/rural_pdf/experiencias.pdf

Rodríguez Ruíz, B. y Rubio MARín, R. «De la paridad, la igualdad y la representación en el estado democrático», Revista Española de Derecho Constitucional, núm. 81, (septiembre-diciembre 2007): 115-159.

SAltzMan, J. Equidad y género. Una teoría integrada de estabilidad y cambio, Ediciones Cátedra, (Madrid, 1992).

SERRA Cristóbal, R. «La presencia de mujeres en los Parlamentos autonómicos. La efectividad de las medidas de paridad adoptadas por los partidos políticos y por el legislador», Revista de Estudios Políticos (Nueva época), núm. 141, Madrid, (Julio-septiembre 2008): 170.

Sevilla Merino, J., Ventura Franch, A. y García Campá, S., «La igualdad efectiva entre mujeres y hombres desde la teoría constitucional», Revista del Ministerio de Trabajo y Asuntos Sociales, 67: 63-81.

TANnen, D. Género y discurso, Paidós, (Barcelona, 1966). 